\title{
Long-Term Predictors of Disease Free Survival (DFS) in Ovarian Cancer Sensitive to Platinum Based Chemotherapy
}

\author{
Prediktor Jangka Panjang dari Disease Free Survival (DFS) pada Kanker Ovarium yang Sensitif \\ terhadap Kemoterapi Platinum \\ Dita Ria Selvyana ${ }^{1 *}$, Johan Kurnianda ${ }^{2}$ \\ ${ }^{1}$ Division of Internal Medicine, Doctor Professional Study Program, Faculty of Medicine and Health Sciences, \\ Universitas Muhammadiyah Yogyakarta \\ 2 Division of Hematology and Medical Oncology, Department of Internal Medicine, Faculty of Medicine \\ Universitas Gadjah Mada/RS.Dr.Sardjito, Yogyakarta
}

DATA OF ARTICLE:

Received: 13 Feb 2019

Reviewed: 27 Mar 2019

Revised: 16 May 2019

Accepted: 21 Jun 2019

*CORRESPONDENCE: deetajogja@yahoo.com

DOI:

10.18196/mm.190232

TYPE OF ARTICLE: Case Report

\begin{abstract}
Until now, there has been progress in the treatment of ovarian cancer, but ovarian carcinoma is still a cause of high mortality. Various factors have been known to be associated with a poor prognosis, such as the absence of symptoms, lack of an effective screening tool, diagnosis of the disease that was only detected after an advanced stage, high recurrence of disease resistant to chemotherapy. There are more than $70 \%$ of cases detected in advanced stage, with long-term survival of only $15-30 \%$; while those detected in early stages, the survival reaches $90 \%$. The recurrence risk of IIIC stage disease is as high as $40 \%-50 \%$. However, there is a small group of patients who can recover after standard therapy. There is variability in the recurrence-free period and survival, so it is difficult to predict the outcome with certainty. Ovarian cancer patients with the same characteristics can show a different prognosis, related to high molecular heterogeneity of tumor genetics. We report a rare case that is a 56-year-old woman who has experienced a 5year free disease after complete remission after standard chemotherapy from stage IIIC ovarian cancer. The disease-free period of up to 5 years after therapy may be related to factors that can be predictors of prognosis, such as age at diagnosis, body mass index, physical performance, cancer cell biology, and the success of surgical response and chemotherapy in these patients.
\end{abstract}

Keywords: Ovarian Cancer; Prognosis Factors; Relapse-free period 
kemungkinan berkaitan dengan faktor yang dapat menjadi prediktor prognosis, seperti umur saat terdiagnosis, indeks massa tubuh, performa fisik, biologi sel kanker, serta keberha silan dari respon terapi pembedahan dan kemoterapi pada pasien tersebut.

Kata Kunci: Kanker Ovarium; Faktor Prognosis; Masa Bebas Kekambuhan

\section{INTRODUCTION}

Although epidemiologically there have been significant developments in the successful management of ovarian carcinomas, the mortality rate caused by the disease is still relatively high. The study conducted by Ezzati M. et al. (2014), ${ }^{1}$ revealed that this is thought to be caused by the condition of patients who are often diagnosed during the advanced phase, the lack of a method of weaning early disease, the initial condition of asymptomatic disease, as well as recurrence of disease that is resistant to chemotherapy.

According to Ezzati M. et al. (2014), recurrence rate of ovarian carcinoma after complete remission after the first chemotherapy series can reach $40 \%$ $50 \%$, where it is very varied and gives a different prognosis even among individuals having similar clinical symptoms.

Efforts to predict recurrence of ovarian carcinoma after complete remission is a challenge, due to the high molecular heterogeneity of the disease. Therefore, Zhang M. et al. (2015), ${ }^{2}$ stated studies related to biology of carcinoma cells may be able to predict therapeutic responsiveness and can help predict long-term Disease Free Survival (DFS) rates.

The main treatment for ovarian cancer with radical cytoreduction surgery is then followed by adjuvant chemotherapy with a standard regimen of paclitaxel and carboplatin. The rate of response to chemotherapy with a median of progression-free survival (PFS) 15-18 months, and median of overall survival (OS) of less than 3 years. Platinum free interval is the most important factor in predicting patient response to second-line therapy, divided into platinum-refractory, platinum-resistant, platinum-sensitive partial, and sensitive platinum. ${ }^{3}$

Here we report a fairly rare case, a 56-year-old woman who has experienced a disease-free period / Disease-free survival (DFS) for 5 years after complete remission after standard chemotherapy from stage IIIC ovarian cancer. DFS that occurs in patients up to 5 years after therapy may be related to various factors that can be predictors of the patient's prognosis, such as age at diagnosis, body mass index, physical performance, biology of cancer cells, and the success of surgical response and chemotherapy in the patients.

\section{CASES}

A 56 years old woman, first came with complaints of abdominal pain in August 2012. Ultrasonography (USG) examination revealed a solid and cystic mass in the posterior uterus with a size of $7.5 \mathrm{~cm} \times 7.0 \mathrm{~cm}$. Ca 125 marker examination showed a result $=1867$, with carcinoembryonic antigen (CEA) 0.85. The patient was then planned to undergo a Total Abdominal Hysterectomy (TAH), Bilateral Salpingo Oophorectomy (BSO) and debulking to undergo a surgical staging procedure.

Based on surgical staging accompanied by an examination of pathological tissue, a picture of multilocular ovarian cystadenocarcinoma of the papilliferum musinosum, with an image of adenocar

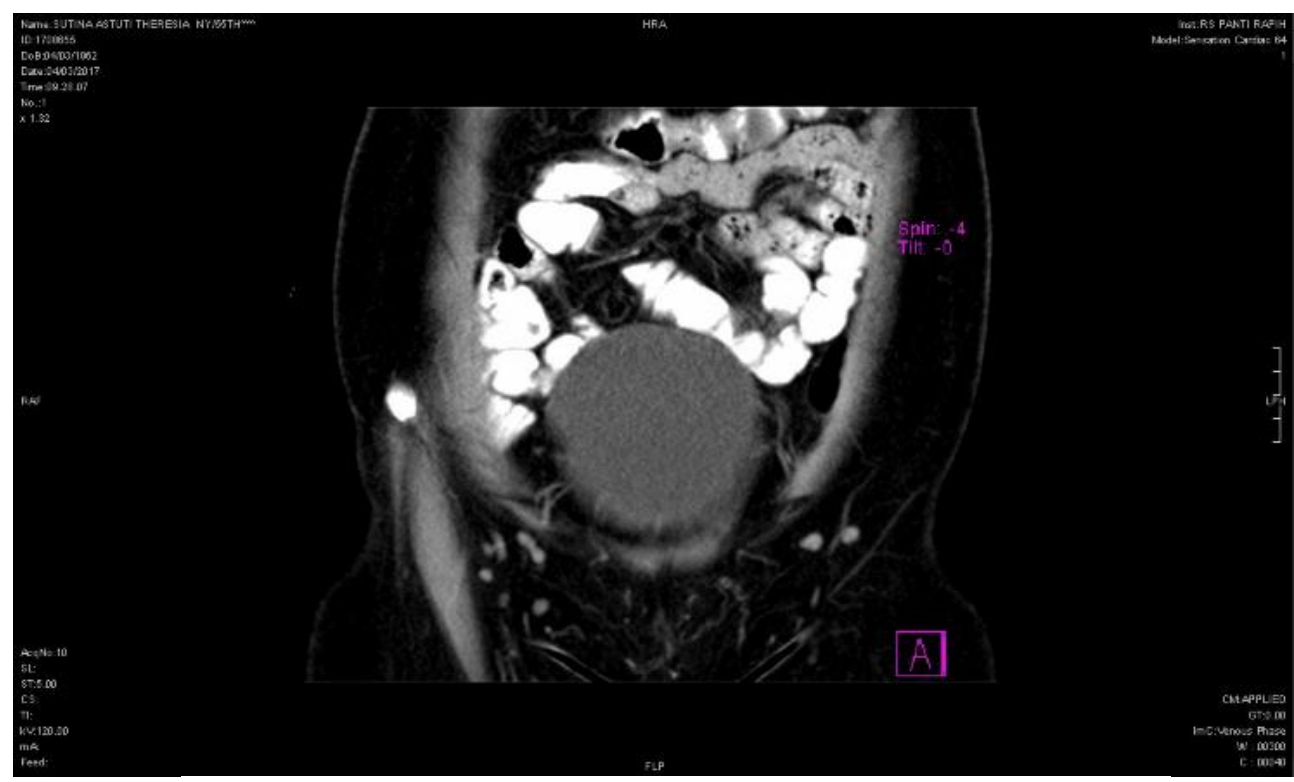

Figure 1. MSCT Patients with Recurrent Tumor Mass in Left Adnexa 
-cinoma in ascitic fluid was obtained. The patient was later diagnosed with stage IIIC ovarian carcinoma. Postoperative examination of CA 125 markers reached 552. The patient then underwent chemotherapy with regimen of paclitaxel $300 \mathrm{mg}$ and $450 \mathrm{mg}$ carboplatin for 6 cycles at intervals of 21 days.

The patient completed chemotherapy thoroughly in December 2012. Post-chemotherapy evaluation with abdominal ultrasound results in the absence of an abdominal tumor mass, with a normal chest X-ray examination. The CA 125 post chemotherapy result was 5.54 . The patient is then determined as Complete Remission of ovarian carcinoma.

Quarterly monitoring in 2013 to 2014 did not find any symptoms and signs that lead to carcinoma recurrence. The six-month evaluation until 2016 found no symptoms and signs that lead to carcinoma recurrence.

In February 2017, the patient again complained of abdominal pain. An ultrasound examination found a tumor mass of $5.21 \mathrm{~cm} \mathrm{x} 3.58 \mathrm{~cm}$, further examination of multi-slice computed tomography (MSCT) of the abdomen found a cystic mass in the left adnexa with a size of $5 \times 4 \mathrm{~cm}$ (Figure 1.). Examination of CA 125 markers obtained results 31.4. Then, the patient is planned to undergo a debulking procedure. Post debulking tissue pathology examination showed results in the form of cystadenoma papiliferum serosum.

\section{DISCUSSION}

Based on the Canadian Cancer Society, there are several factors which determine the prognosis dan survival and possible recurrence of ovarian carcinoma. ${ }^{4}$

Table 2. explained several prognostic factors such as stadium carcinoma, carcinoma cell findings in peritoneal fluid, the spread of intra-abdominal tumor CA-125 marker concentration, obesity, age of physical performance, tumor type, responsiveness to chemotherapy, immunological factors, and the molecular profile of carcinoma cells. ${ }^{5}$

Carcinoma stadium when the diagnosed happened is the most important determinant factor which determines the prognosis of the disease. Early carcinoma provides a better prognosis when compared to the advanced stadium. According to Ezzati M. et al. (2014), ${ }^{1}$ related to the prognosis of ovarian carcinoma, concluded that stadium IA ovarian carcinoma having a survival rate in 5 years reached $94 \%$ while stadium IV having a survival rate in 5 years reached $18 \%$. In this patient, the stadium at the time of diagnosis was stadium III C which has
Table 1. Survival of Ovarian Cancer Patients

\begin{tabular}{cc}
\hline Stadium & 5-year survival \\
\hline I & $90 \%$ \\
IA & $94 \%$ \\
IB & $92 \%$ \\
IC & $85 \%$ \\
II & $70 \%$ \\
IIA & $78 \%$ \\
IIB & $73 \%$ \\
IIC & $57 \%$ \\
III & $39 \%$ \\
IIIA & $59 \%$ \\
IIIB & $52 \%$ \\
IIIC & $39 \%$ \\
IV & $17 \%$ \\
\hline
\end{tabular}

a prognosis of survival rate in 5 years reaching $39 \%{ }^{1}$

According to Ezzati M. et al. (2014), ${ }^{1}$ the presence of carcinoma cells in ascites or peritoneum washing results indicates a worse prognosis compared to the absence of carcinoma cell. In this patient, ascites formation was found, with ascitic fluid cytology analysis showing the presence of carcinoma cells suggestive of adenocarcinoma.

Ezzati M. et al. (2014), ${ }^{1}$ explain the spread of carcinoma cells to the abdominal and pelvic wall associated with a worse prognosis compared to the absence of the proliferation of carcinoma cells. In this patient, tumor cell infiltration was found in the post-DFS pelvis for five years. The process can occur as a result of the metastasis process or as a result of a process called Ovarian Remnant Syndrome (ORS), which occurs as a result of excision of the incomeplete from ovarian carcinoma tissue. According to Imai A, Matsunami K, Takagi $\mathrm{H}$ et al. (2014), ${ }^{6}$ incidence of ORS generally occurs within a median of 12-13 years (range of 2-54 years). The way to differentiate postoperative pelvic/abdominal tumor lesions/chemotherapy ovarian carcinoma is to use tissue histology and FSH concentration. FSH concentrations $<40 \mathrm{mlU} / \mathrm{ml}$ in patients who got the BSO procedure can lead to the diagnosis of ORS (In this patient, post-debulking histological tissue examination for the indications of the finding of tumor cell infiltration on the pelvis produced a result in the form of cystadenoma serosum papiliferum). ${ }^{6}$

The examination of grade tumor also helps in knowing the prognosis of patients with ovarian carcinoma as a result of this examination, which reflects on the biology of the tumor cells. According to Ezzati M. et al. (2014), ${ }^{1}$ high-grade tumor tend to have a worse prognosis compared to low-grade tumors. In this patient, no further analysis was carried out related to the degree of differentiation 
Table 2. Prognostic Factors of Ovarian Carcinoma

\begin{tabular}{ll}
\hline \multicolumn{1}{c}{ Determinant factor } & \multicolumn{1}{c}{ Conditions with a good prognosis } \\
\hline Carcinoma Stadium & Early Stadium \\
Findings and Spread of Carcinoma cell & $\begin{array}{l}\text { There are no carcinoma cell findings in ascites and abdominal } \\
\text { spread }\end{array}$ \\
Grade tumor & Low-grade tumor \\
Debulking & Optimal debulking \\
Concentration of CA-125 & Decreased CA-125 concentration after chemotherapy \\
Obesity, age, physical performance & No obesity, young, good physical performance \\
Chemotherapy response & Complete remission \\
Carcinoma cell subtype & Endometrioid and musinosum \\
Immunological factors & Tumor infiltrating lymphocytes findings \\
Molecular profile & $\bullet \quad$ XRCC1 deficiency \\
& $\bullet \quad$ homologous recombinant deficiency \\
& $\bullet \quad$ The Increase of expressions of Her2, KRAS and EGFR \\
& $\bullet \quad$ The decrease of expressions of BRCA1 and BRAF \\
\hline
\end{tabular}

of tumor cells.

Ezzati M. et al. (2014), explained the results of effective therapy from the debulking process also influence the prognosis of patients with ovarian carcinoma. Patients with optimal debulking had a significantly higher survival rate compared to the group of patients with suboptimal debulking. Furthermore, the size of the remaining tumor cells in the group of patients who got suboptimal debulking also influences the patient's prognosis. Residual lesions of $<0.5 \mathrm{~cm}$ have a survival rate of up to 56 months, while residual lesions of $>0.5 \mathrm{~cm}$ have a survival rate of up to 27 months $(P<.001){ }^{1}$ The success of debulking (optimal/suboptimal) can also be predicted by the expression of the p53 gene, where tumors that express that gene tend to be difficult to achieve the optimal debulking of patients who have undergone the optimal debulking operative procedure. ${ }^{7}$

Decreased concentrations of CA-125, according to Ezzati M. et al. (2014), ${ }^{1}$ has significant prognostic value. The decrease in CA-125 concentration after chemotherapy showed excellent responsiveness to chemotherapy and be a marker of a better prognosis compared to without changes in CA-125 level after therapeutic action. In this case report, the patient experienced a significant decrease in CA-125 concentration after surgery and chemotherapy. ${ }^{1}$

Obesity also affects prognosis in patients with ovarian carcinoma. Some related studies are Diaz ES, Karlan BY, Li AJ. (2013). ${ }^{8}$ They concluded that the risk relative to the aspect of mortality obtained results in the form of 1.5 times higher mortality risk in ovarian carcinoma patients with a body mass index above $35 \mathrm{~kg} / \mathrm{m}^{2}$ compared to the group of patients with a healthy body mass index. These findings are thought to be related to overexpression of the hormone leptin, where leptin is known to increase the progression of some types of carcinomas. In this patient, obesity was not found.

The age factors also have a significant effect on the prognosis and recurrence rate of ovarian carcinoma. The ovarian carcinoma that occurs at the age of fewer than 65 years is associated with a median survival time that can reach two years longer, has a good level of tumor cell differentiation, and is less invasive when compared to ovarian carcinoma that occurs over the age of 65 years. Also, research conducted by Ezzati M., et al. (2014), revealed ovarian carcinoma that occurred at age $>$ 65 years associated with more comorbid diseases and more reduced physical performance. In this patient, the diagnosis of the patient's ovarian carcinoma is established at the age of 56 years. ${ }^{1}$

Ezzati M. et al. (2014), ${ }^{1}$ explains the status of physical performance in patients with ovarian carcinoma adopting the physical performance assessment system from the Eastern Cooperative Oncology Group/World Health Organization. The assessment was carried out by dividing the patient's physical performance into five classification assessments, i.e., 0: asymptomatic, 1: symptomatic but can complete outpatient therapy, 2: symptomatic, spend $<50 \%$ in bed during the day, 3: symptomatic, ordain activity $>50 \%$ in bed during the day, and 4 : spend the whole activity in bed. Patients with poor physical performance are associated with more inadequate therapeutic responses and more substantial side effects than those in the group of patients who have functional performance status. This patient has the performance status of equivalent to the value of 1 calibration.

According to Ezzati M. et al. (2014), ${ }^{1}$ responsiveness from chemotherapy is related to the prognosis of the patient. The complete therapeutic response after first cycle chemotherapy is associated with a good prognosis. The patient reaches com- 
plete remission after chemotherapy. This result indicates the responsiveness of treatment is adequate and represents a good prognosis.

The histological type of carcinoma cells in ovarian carcinomas can represent the prognosis of the disease. This study shows that every kind of histological picture of carcinoma cells correlates with different prognoses. For example, research conducted by Prat J. (2012), ${ }^{9}$ that high-grade serous tumors have a poor prognosis, whereas the type of musinosum is associated with a good prognosis. Nevertheless, the type of musinosum has a reasonably low prevalence, which is $2-4 \%$ of all cases of ovarian carcinoma, with the majority of cases (90\%) from the type of musinosum which have tumor cell types of low differentiation (low-grade tumor). This finding is related to a good prognosis, relatively small mortality with a five years survival rate that can reach $90 \%$. Nevertheless, cases of recurrence or metastasis of the type of musinosum are associated with a poor prognosis and the possibility of metastases occurring in unexpected places such as the bones or lungs. ${ }^{10}$ In this patient, the type of carcinoma cell that appears is the type of mucinosum. In addition, patients also experience recurrence of cases of the type of musinosum.

The existence of intratumoral lymphocyte $T$ cell findings is a marker of immune cell sensitivity to resistant cell growth, which is a marker of a good prognosis. Patients with intra-tumoral lymphocyte $T$ cells have an Overall Survival (OS) value that reaches 2.8 times greater and a Growth Free Survival (PFS) that reaches 3.9 times greater than the control. It also seems to be related to the optimization status of the debulking operative action, where the presence of lymphocyte $T$ cell infiltration combined with the optimal operative work is associated with a good prognosis (Figure 2. \& Figure 3.). ${ }^{11}$ In this case report, the patient was not examined for intratumoral T lymphocyte infiltration.

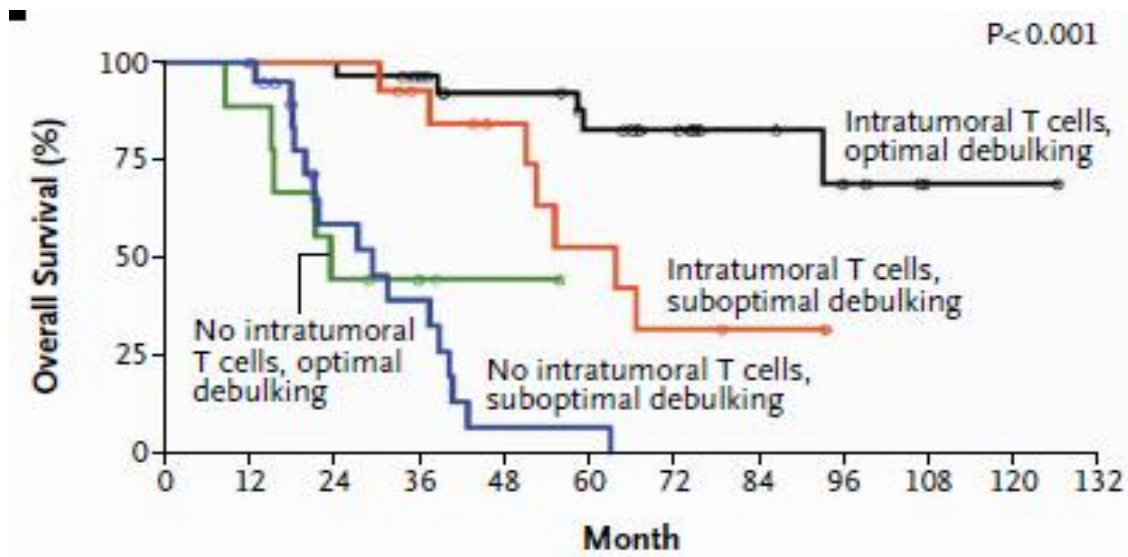

Figure 2. Overall survival values of ovarian carcinomas with and without T cell lymphocyte infiltration and its relation to the optimization of debulking

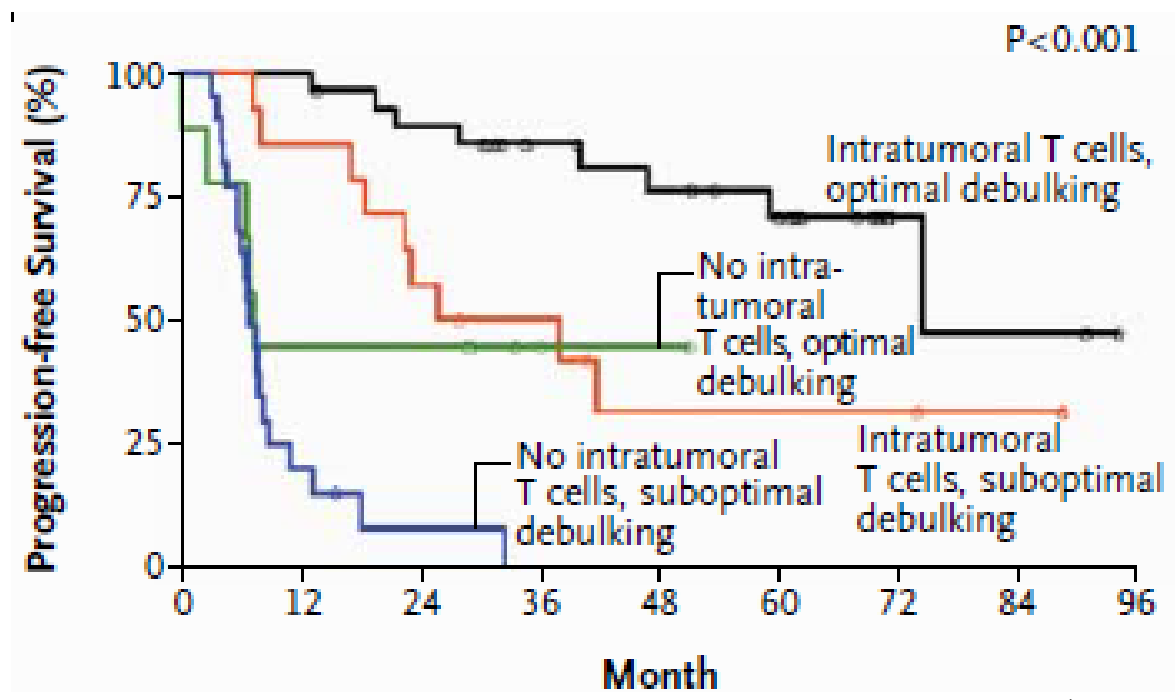

(Zhang L, et al., 2003) $)^{11}$

Figure 3. Progress Free Survival Value of Ovarian Carcinoma with and without Clilocyte T Cell Infiltration and its Relation to Debulking Optimization 
A series of examinations of carcinoma gene profiles can be used to determine the prognosis of ovarian carcinoma, where the biology of carcinoma cell DNA that is damaged after chemotherapy/ radiotherapy can be a marker of the prognosis of ovarian carcinoma. According to Ezzati $M$. et al. (2014), ${ }^{1}$ it was found that (X-ray repair crosscomplementing gene 1 (XRCC1) plays a vital role in the process of DNA repair after chemotherapy/radiotherapy. The deficiency of expression of these genes is a marker of an excellent therapeutic prognosis. Other studies have also found that some gene expression such as increased expression of Her2, KRAS, EGFR and decreased expression of the BRCA1 and BRAF genes are associated with a good prognosis. In this case report, the patient was not examined for gene profiles then, the impact on disease recurrence is unknown. ${ }^{1}$

\section{CONCLUSION}

Various determinants are known to help know the prognosis of ovarian carcinoma. Some of these factors include age, obesity, distribution of cancer cells in the pelvic/intra-abdominal cavity, optimization of debulking, decreased CA-125 concentration after chemotherapy, physical performance, type and differentiation of carcinoma cells, intratumoral lymphocyte $T$ cell infiltration, and various specific gene profiles. In this patient, multiple factors were found and were associated with good prognosis and long-term DFS including complete debulking, decreased CA-125 concentration after chemotherapy, age $<65$ years, no obesity, the excellent physical performance achieved remission complete post-chemotherapy and histopathological subtypes of the musinosum. Another parameter that can be done to determine the prognosis and predictors of long-term DFS with cost and easy access to do is by checking the intratumoral lymphocyte $\mathrm{T}$ cell infiltration.

\section{REFERENCES}

1. Ezzati M, Abdullah A, Sariftrabizi A, Hou J, Kopf M, Stedmen JK, et al. Recent Advancements in
Prognostic Factors of Epithelial Ovarian Carcinoma. Int Sch Res Notices, 2014; 1-10.

2. Zhang M, Zhuang G, Sun X, Shen Y, Zhao A, Di W. Risk Prediction Model for Epithelial Ovarian Cancer Using Molecular Markers and Clinical Characteristics. J Ovarian Res, 2015; 8 (1): 67.

3. Luvero D, Milani A, Ledermann JA. Treatment Options in Recurrent Ovarian Cancer: Latest Evidence and Clinical Potential. Ther Adv Med Oncol, 2014; 6 (5): 229-39.

4. Canadian Cancer Society's Advisory Committee on Cancer Statistics. Canadian Cancer Statistics, 2017. Toronto. 2017. ON: Canadian Cancer Society. Read more: http://www.cancer.ca/en/cancerinformation/cancer type/ovarian/statistics/?region=bc\#ixzz5rOL4vKjj.

5. Landruma LM, Java J, Mathews CA, et al., Prognostic factors for stage III epithelial ovarian cancer treated with intraperitoneal chemotherapy: A Gynecologic Oncology Group study. Gynecol Oncol. $2013 \quad$ July; 130(1): 12-18. DOI:10.1016/j.ygyno.2013.04.001.

6. Imai A, Matsunami K, Takagi H, Ichigo S. Malignant Neoplasia Arising from Ovarian Remnants Following Bilateral SalpingoOophorectomy (Review). Oncology Lett, 2014; 8 (1): 3-6.

7. Fader AN, Rose PG. Role of Surgery in Ovarian Carcinoma. J Clin Oncol, 2007; 25 (20): 28732883.

8. Diaz ES, Karlan BY, Li AJ. Obesity-Associated Adipokines Correlate with Survival in Epithelial Ovarian Cancer. Gynecol Oncol, 2013; 129 (2): 353-357.

9. Prat J. New Insights into Ovarian Cancer Pathology. Ann Oncol, 2012; 23 (Supplement 10): $\mathrm{x} 111-\mathrm{x} 117$.

10. Gurung A, Hung T, Morin J, Gilks CB. Molecular Abnormalities in Ovarian Carcinoma: Clinical, Morphological and Therapeutic Correlates. Histopathology, 2013; 62 (1): 59-70.

11. Zhang L, Conejo-Garcia JR, Katsaros D, Gimotty PA, Masobrio M, Regnani G. Intratumoral T Cells, Recurrence, and Survival in Epithelial Ovarian Cancer. N Engl J Med, 2003; 348 (3): 203 13. 